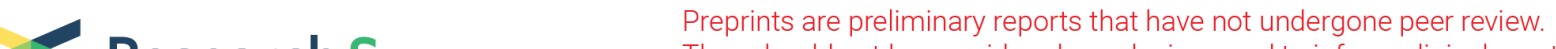 Research Square They should not be considered conclusive, used to inform clinical practice, or referenced by the media as validated information.
}

\section{An 192 bp ERV Insertion in the First Intron of TLR6 Acts as an Enhancer to Increase TLR6 and TLR1 Expression}

\section{xiaoyan wang}

Yangzhou University https://orcid.org/0000-0001-8521-2974

\section{Zixuan Chen}

Yangzhou University

\section{Eduard Murani}

Leibniz Institute for Farm Animal Biology: Leibniz-Institut fur Nutztierbiologie

\section{Enrico D'alessandro}

University of Messina:Department of Veterinary Science

\section{Yalong An}

Yangzhou University

\section{Cai Chen}

Yangzhou University

Kui Li

Chinese Academy of Agricultural Sciences

\section{Grazia Galeano}

University of Messina:Department of Veterinary Science

\section{Klaus Wimmers}

Leibniz Institute for Farm Animal Biology: Leibniz-Institut fur Nutztierbiologie

Chengyi Song ( $\nabla$ cysong@yzu.edu.cn )

Yangzhou University https://orcid.org/0000-0002-0488-4718

\section{Research}

Keywords: Pig, Retrotransposon, RIP, ERV, TLRs, TLR6, Enhancer, Expression, Polymorphism

Posted Date: December 4th, 2020

DOl: https://doi.org/10.21203/rs.3.rs-105672/v1

License: (c) (i) This work is licensed under a Creative Commons Attribution 4.0 International License. Read Full License 
Version of Record: A version of this preprint was published at Mobile DNA on August 18th, 2021. See the published version at https://doi.org/10.1186/s13100-021-00248-w. 


\section{Abstract}

\section{Background}

Toll-like receptors (TLRs) play important roles in building innate immune and inducing adaptive immune responses. Associations of the TLR gene polymorphisms with diseases susceptibility, which are the basis of molecular breeding for disease resistant animals, have been reported extensively. Retrotransposon insertion polymorphisms (RIPs) were developed recently as a new type of molecular marker having great potential in population genetics and quantitative trait locus (QTL) mapping analysis. In this study, bioinformatics prediction combined with the PCR-based amplification was employed to screen for RIPs in porcine $T L R$ genes. Their population distribution and impact on gene activity and phenotype of one RIP was been further evaluated.

Results

The results showed that five RIPs, located at the $3^{\prime}$ flank of $T L R 3,5^{\prime}$ flank of $T L R 5$, intron 1 of $T L R 6$, intron 1 of $T L R 7$, and $3^{\prime}$ flank of $T L R 8$ respectively, was identified. These RIPs were detected in different breeds with an uneven distribution among them. By using the dual luciferase activity assay a $192 \mathrm{bp}$ endogenous retrovirus (ERV) in the intron 1 of TLR6 was proven to act as an enhancer increasing the activities of TLR6 promoter and multiple mini-promoters. Furthermore, the real-time quantitative polymerase chain reaction (qPCR) analysis demonstrated that the ERV insertion significantly enhances the mRNA expressions of $T L R 6$, the neighboring gene TLR1, and the downstream genes MyD88 (Myeloid differentiation factor 88), Rac1 (Rac family small GTPase 1), TIRAP (TIR domain containing adaptor protein), Tollip (Toll interacting protein) of TLR signaling pathway and the inflammatory factors IL6 (Interleukin 6), IL8 (Interleukin 8), and TNFa (Tumor necrosis factor alpha) in 30-day piglet tissues. In addition, the serum IL-6 and TNFa was also significantly upregulated by ERV insertion.

\section{Conclusions}

Overall, five RIPs were been identified in several TLRs, and the $192 \mathrm{bp}$ ERV insertion in the first intron of $T L R 6$ can improve the expressions of $T L R 6, T L R 1$, their downstream genes, and the inflammatory factors by acting as an enhancer affecting the regulation of TLR pathways, which may be applicable in the molecular breeding of disease resistant animals.

\section{Background}

Toll-like receptors (TLRs) play profound roles in motivating innate and adaptive immune responses. Protein(s) encoded by TLRs genes are important due to their ability of recognizing different types of pathogens and associated molecular patterns[1]. Polymorphisms in TLR loci and their influence on either susceptibility or resistance to major human infectious diseases, including tuberculosis, leishmaniasis, malaria, filariasis, some autoimmune endocrine diseases, have been reported extensively[2-4]. It has been reported that C1174T of TLR5 resulted in a common stop codon polymorphism and produced significantly lower levels of proinflammatory cytokines in comparison with individuals with the wild-type genotype which 
indicated that the TLR5 stop codon polymorphism is associated with protection from the development of systemic lupus erythematosus[5]. The missense mutation of TLR1 rs5743618, specific in Europeans can change the expression of 81 genes involved in the inflammatory response[6]. Chikungunya patients with rs179010-CC genotype of TLR7 showed significantly high interferon alpha 1 (IFN-a) level, which might act as potential prognostic biomarkers for predicting Chikungunya susceptibility [7]. It is commonly accepted that TLRs are important candidate genes for some human diseases.

For domesticated farm animals, TLRs also have been suggested as the most promising candidate genes for immunity improvement or disease resistance by molecular breeding[8]. Genetic variants of TLRs associated with cattle mastitis, mycobacterial infection, and paratuberculosis have been identified[9-11]. Totally, ten $T L R s$ in the pig genome were annotated and SNP screening in the pig TLRs and their expression patterns in immunity organs have been reported extensively[12]. It has been suggested that piglets with the $T$ allele of TLR5 (C1205T) exon exhibit impaired resistance to Salmonella typhimurium infection[13]. C506W of TLR4 exon in Japanese wild boar populations caused loss of ability to induce nuclear factor-kB activation after lipid A stimulation[14-16]. Association between SNPs in TLR4 and TLR5 with transcription levels of cytokines indicate that these SNPs are related to the modulation of the cytokine mediated immune response. Until now, all studies were focusing on the associations of SNPs in TLRs with diseases susceptibility, reports for retrotransposon insertion polymorphism in TLRs and their genetic effects are not available.

Retrotransposons are important components of plants and mammal genomes, which account for nearly half of the mammal genomes[17,18], and can mobilize themselves to new genomic locations and generate polymorphic insertions. Retrotransposons can further be classified into LTR (Long Terminal Repeat elements, including endogenous retrovirus, ERV) and non-LTR (including LINE, Long Interspersed Nuclear Elements; and SINE, Short Interspersed Nuclear Elements)[19]. For a long time, transposable elements including retrotransposon has been considered as genomic parasites[20,21]. However, recently, more and more evidences support that retrotransposons contribute to genome architecture and evolution even maintenance of three-dimensional chromatin organization in mammals[18,22-24].

Retrotransposon Insertion Polymorphism, RIPs, have been applied for genomic evolution and genetic diversity evaluations in plants as molecular markers[25,26]. For human, RIPs have been identified as causative mutations for some diseases[27]. By genome-wide association studies, an intronic Alu insertion polymorphism inserted in the $97 \mathrm{bp}$ downstream of a CD58 exon is on a haplotype associated with multiple sclerosis risk due to the Alu insertion altering mRNA splicing[28,29].

For domestic animals, RIPs also have been used for evolution and population genetic analysis of sheep[30], deer[31], cat[32], chicken[33], and rabbit[34]. Several RIPs have been defined as the causative mutations for phenotype variations. An ERV insertion in the 5 ' flanking region of $S \angle C O 1 B 3$ causes blue eggshell by promoting the expression of SLCO1B3 gene in the uterus (shell gland) of the oviduct in chicken[35,36]. The henny feathering allele harbors an insertion of an intact avian ERV at the 5'end of CYP19A7[37]. The SINE insertion in follicle stimulating hormone beta $(F S H \beta)$ and protein disulfide isomerase associated 4 (PDIA4) genes were associated with litter size variation in pigs[38,39]. 
In the current study, the contribution of RIPs to the structural variations of TLR genes, the breed distribution of these RIPs and exemplarily the genetic effect of one RIP was investigated. We identified five RIPs for 10 TLR genes, and our data suggest that one RIP plays role in the regulation of TLR pathway by acting as an enhancer. These findings will contribute to the understanding the role of RIPs in the pig genomic and genetic variation, and one RIP may be useful for disease resistance selection in the pig breeding.

\section{Results}

\section{Five RIPs generated by retrotransposon insertions in the pig TLR gene cluster}

Ten $T L R$ genes and their flanking sequences from sixteen assembled pig genomes, representing lean type pigs (Cross-breed of Yorkshire/Landrace/Duroc, Duroc, Landrace, Yorkshire, Pietrain, Berkshire, and Hampshire), fat type pigs (Rongchang, Meishan, Bamei, and Jinhua), and miniature pigs (Bama, Wuzhishan, Tibetan, Goettingen, and Ellegaard Gottingen) were used for screening of structural variations by alignment with ClustalX program (version 2.0)[40]. Totally, we identified 53 large SVs (more than 50 bp and less than $1000 \mathrm{bp}$ ) or large frameshift variants (more than 1000bp), and 35 of them were predicted as retrotransposon insertion polymorphisms, including 15 SINE, 11 ERV and 6 LINE insertions, which were summarized in additional file 1 (Table S1). Then all these predicted insertions were further been evaluated by wet PCR via the specific primer pairs spanning the insertions in pooled samples. Finally, 5 RIPs, including 2 SINE insertions, 2 ERV insertions and 1 Line insertion, were obtained by using 11 domesticated pig breeds and wild boar samples (Fig. 1A). All these insertions were been confirmed again by TA cloning and sequencing. One 288 bp and one 294 bp SINE insertions in the 3' flanks of TLR3 and TLR8 were detected, respectively. Moreover a single 357 bp L1 insertion in the $5^{\prime}$ flank of $T L R 5$ was found, and in addition two ERV insertions were detected, one $192 \mathrm{bp}$ and one $413 \mathrm{bp}$ in first intron of TLR6 and TLR7 were identified, respectively. We named those insertions as TLR3-SINE-RIP, TLR5-LINE-RIP, TLR6-ERV-RIP, TLR7-ERV-RIP, and TLR8-SINE-RIP, respectively (Fig.1B and 1C).

\section{RIP distribution in different pig breeds}

A total of eleven breeds (Duroc, Landrace, Yorkshire, Erhualian, Meishan, Fengjing, Bama, Tibetan,Wuzhishan, Diannan small-ear and Sujiang) were used for all RIPs evaluation, while extra breeds, the Sicilian black from Italy and the Landrace and the Yorkshire from Germany, were used for TLR6-ERV-RIP evaluation. For breeds displaying polymorphic RIPs in Fig.1 an additional individual samples were tested (Table 1). The PCR genotyping revealed that TLR3-SINE-RIP in six breeds (Duroc, Erhualian, Bama, Tibetan, Meishan, and Fengjing), TLR5-LINE-RIP in three breeds (Duroc, Yorkshire, and Wuzhishan), TLR6-ERV-RIP in three breeds (Sujiang, Bama, and Fengjing), TLR7-ERV-RIP in two breeds (Landrace and Wuzhishan), and TLR8-SINE-RIP in four breeds (Landrace, Yorkshire, Sujiang, and Wuzhishan) display polymorphisms. Most RIPs in most breeds were in Hardy-Weinberg equilibrium ( $P>0.05)$, while TLR3-SINE-RIP in Meishan, TLR6ERV-RIP in Sujiang and Fenjing, TLR7-ERV-RIP in Landrace, TLR8-SINE-RIP in Wuzhishan deviated from the Hardy-Weinberg equilibrium $(P<0.05)$. The SINE ${ }^{+/+}$genotype of $T L R 3-S I N E-R I P$ in Duroc and Tibetan, the ERV $^{-/}$genotype of TLR6-ERV-RIP in Fengjing, and the ERV ${ }^{+/+}$genotype of TLR7-ERV-RIP in Landrace and Wuzhishan were not detectable. As for polymorphic information content (PIC), RIPs in most breeds display 
moderate polymorphism (ranging from 0.239 to 0.375 ), except for the Duroc and the Tibetan, where TLR3SINE-RIP shows low polymorphism (low than 0.150).

\section{Evidence of enhancer activity of the $192 \mathrm{bp}$ ERV insertion near the core promoter of TLR6}

Both of TLR6 and TLR7genes contain an ERV insertion in the first intron, and further analysis revealed that the 192 bp ERV insertion was near the core promoter region of $T L R 6$, and diverse regulatory elements such as $\mathrm{CpG}$ islands and transcription factor binding sites (Fig. 2A). To further evaluating the potential roles of ERV insertions in the regulation of TLR6 activity, the core promoter regions with or without the 192 ERV insertion allele was been cloned into a luciferase reporter vector (pGL3-Basic), respectively (Fig.2B), and then submitted for luciferase activity evaluation. The dual luciferase activity assay revealed that the ERV insertion significantly improved the promoter activity of $T L R 6$, the luciferase activity in cells transfected with the vector with EVR insertion allele $\left(T L R 6^{\mathrm{ERV}+}{ }_{-} \mathrm{Luc}(\mathrm{En})\right)$ were almost two times $(P<0.01)$ than that without ERV insertion allele (TLR6 ${ }^{\text {ERV-}}$-Luc(En)) in both porcine PK15 and human Hela cells (Fig. 2C), which suggested that the $192 \mathrm{bp}$ ERV may act as an enhancer in the regulation of TLR6 activity. To further confirm this deduction, we evaluated the enhancer activity of the ERV insertion by cloning it into the luciferase reporter vector containing mini-promoter, but absent SV40 enhancer, which is generally used for enhancer activity evaluation. Two type mini-promoters ( $\beta$-globin, and OCT4) were been evaluated, and the schematic diagram of vectors were shown in Fig.3A. Again, the luciferase activity assay revealed that the ERV insertion allele significantly improve all these mini-promoter activities in both PK15 (Fig.3B) and Hela cell lines (Fig.3C). These data strongly support that the 192 bp ERV insertion acts as an enhancer and may be involved in the regulation of TLRs.

\section{ERV insertion alter the expression of pig TLR6 and TLR1 and their downstream genes in multiple tissues}

To further illustrate the biological roles of the $192 \mathrm{bp}$ ERV insertion in the Toll like receptor signaling pathway, we investigated the mRNA expressions of $T L R 6$ and $T L R 1$, which are neighboring genes located on chromosome 8, and their downstream genes (MyD88, Rac1, TOLLip, TIRAP, IL-6, IL-8, and TNFa) in the same pathway by qPCR in multiple tissues (liver, spleen, lung and kidney) for different genotypes in 30-day piglets. The qPCR results revealed that, generally, the ERV insertion improve the expression of TLR6 and TLR1 in these tissues. In detail, in the spleen, kidney and liver tissues, the expression of TLR6 and TLR1 in the pigs with $\mathrm{ERV}^{+/+}$genotype were significantly higher $(P<0.05)$ than that in those animals with $\mathrm{ERV}^{+/-}$and $\mathrm{ERV}^{-/-}$ genotypes. In lung, there were significant expression differences $(P<0.01)$ of $T L R 6$ between the $\mathrm{ERV}^{+/+}$ animals and the ERV ${ }^{-1}$ animals (Fig.4A and 4B). MyD88, Rac1, TOLLip and TIRAP are the downstream genes of $T L R 6$ and $T L R 1$ in the Toll like receptor signaling pathway and play key roles in innate immune mechanisms as central molecules. The qPCR results revealed that ERV insertion enhanced the expressions of most downstream genes of TLRs. In detail, in the spleen, lung and kidney, the expression levels of MyD88 and Rac1 were significantly higher $(P<0.05)$ in the animals with $\mathrm{ERV}^{+/+}$than in the animals with $\mathrm{ERV}^{+/-}$and $\mathrm{ERV}^{-/}$genotypes (Fig.4C and 4D). Expression of TIRAP and Rac1 in liver, lung and kidney of ERV ${ }^{+/+}$ homozygous animals were significantly $(P<0.05)$ higher than those of heterozygote $\left(\mathrm{ERV}^{+/}\right)$and 
homozygote $\left(\mathrm{ERV}^{-/}\right)$animals. In spleen, significantly $(P<0.05)$ difference was only observed for the expression of TIRAP gene between homozygotes $\mathrm{ERV}^{+/+}$and $\mathrm{ERV}^{-/}$animals (Fig.4E and $4 \mathrm{~F}$ ). Inflammatory factors $I L-6, I L-8, T N F a$ are important genes in the end of Toll like receptor signaling pathway. The expression of TNFa, IL-6, IL-8 increased significantly $(P<0.05)$ in the spleen, lung and kidney of homozygous of $\mathrm{ERV}^{+/+}$compared with that in $\mathrm{ERV}^{-/-}$genotype piglets (Fig.4G, 4H, 4I). These results indicated that the 192 bp ERV insertion allele near the core promoter of TLR6 increases not only the expressions of TLR6 and $T L R 1$, but also the expressions of the downstream genes of the TLR signaling pathway.

\section{Impact of ERV insertion on the serum immune cytokine}

To investigate the impact of the ERV insertion allele near the core promoter of TRL 6 on the immune response, several serum immune cytokines were measured by ELISA for different genotypes of 30-day piglets. The ELISA analysis revealed that, consistent with the higher expression of IL- 6 and TNFa in the important immune tissues (spleen and kidney) of $\mathrm{ERV}^{+/+}$piglets compared that in other genotype piglets $\left(\mathrm{ERV}^{+/-}\right.$and $\left.\mathrm{ERV}^{--}\right)$, the serum concentrations of IL-6 and TNFa in the animals with $\mathrm{ERV}^{+/+}$genotype were also significantly higher than that in the $\mathrm{ERV}^{-1-}$ genotype animals $(P<0.05)$ (Fig.5). But there is no significant difference of serum IL8 among different genotype.

\section{Discussion}

Retrotransposons are dominant components in most land plant genomes and mammals[18,26,41] and regarded as important drivers of species diversity and putative actors in evolution and adaptation[26,4244]. Various methods, such as inter-retrotransposon amplified polymorphism (IRAP) and retrotransposonmicrosatellite amplified polymorphism (REMAP), have been developed to exploit RIPs[45]. They have been successfully applied in the studies of plant genetic diversity and QTL mapping[46]. Furthermore, some RIPs have been proved as a causal mutation to change the plant phenotype[47-49]. It is believed that SINE of RIPs are "nearly ideal" genetic markers to facilitate plant breeding[50]. In domestic animals, RIPs also have been applied to genetic diversity, evolution and variety identification, and display great potentials in animal molecular breeding. Our previous study revealed that LINE, LTR, and SINE are highly enriched in the pig genome, and totally account for about $37.13 \%$ of the genome sequence[51]. According to the insertion age analysis, differential evolution profiles were been observed for different families and subfamilies of retrotransposons. Most retrotransposons in the pig genome are ancient and no longer jumping, and cannot generate polymorphic insertions in populations, whereas some of them were thought to be younger retroelements, such as SINEA, L1D, ERV6 subfamilies[51]. These retrotransposons still play roles in shaping genomes and gene evolution and contribute to the genomic variations and their insertions tend to generate polymorphisms, which can be used as genetic markers. In addition, it has been suggested that transposable elements affect the genome in both destructive and constructive ways[41]. Natural selection and genetic drift could shape the distribution and accumulation of TEs and insertions with destructive effects are rapidly removed from the population[52]. In the current study, we identified five RIPs in TLRs genic and flanking regions by alignment and combining the PCR validation. They located in different genic positions including introns, $5^{\prime}$ and $3^{\prime}$ flank of TLRs. Two ERV insertions, One of $192 \mathrm{bp}$ and the other of $413 \mathrm{bp}$ in length were identified in the first intron of both TLR6 and TLR7, respectively, and based on the bioinformatics analysis, 
the $192 \mathrm{bp}$ ERV insertion in the intron 1 of $T L R 6$ was predicted to be in the core promoter region, which may influence the gene expression. Since the ERV insertion fragment contained the U3-R-U5 sequences, which were thought to act as transcriptional regulators because of U3 region [53], it may act as enhancer or promoter that could be involved in the regulation of expression pattern of target genes[54-56]. Here, the luciferase assay analysis strongly supported that the 192bp ERV insertion serves as an enhancer, which not only can increase the TLR6 promoter activity, but also can improve the activities of diverse mini-promoters.

Population distribution analysis of these RIPs revealed that most loci are in genetic equilibrium, while some polymorphic insertion loci (TLR5-LINE-RIP) are in genetic disequilibrium, indicating that these loci may have experienced strong selection and play biological roles in gene regulation and phenotype variation. TLR6ERV-RIP in Sujiang and Fenjing deviated from the Hardy-Weinberg equilibrium $(P<0.05)$, indicating that this locus may have experienced strong purification selection considering the ERV insertion playing positive roles in the immune response. The deletion allele of TLR6-ERV-RIP were only found in China native pig breeds (Bama, Fenjing) or cross breeds of Sujiang (Durocx JiangquhaixFengjing), while all analysed western pigs including Landrace, Yorkshire, Duroc, and Sicilian Black from Italy are monomorphic and only contain the ERV insertion allele $\left(E R V^{+}\right)$, suggesting that the deletion allele (ERV) seems to originate from Asian pig breeds. Base on the positive effect of this allele on the disease resistance, it can be used to improve the disease resistance performance (such as Sujiang) or to be introduced into other China native breeds with marker assisted selection.

An age of 30 days is an important stage for pig to develop the adaptive immunity[57]. We further evaluated the expression of $T L R 6$ and $T L R 1$, which is a nearby gene of $T L R 6$ with only $4.2 \mathrm{~kb}$ far away, in different tissues of 30-days piglets between different ERV insertion genotypes. The QPCR analysis demonstrated that the mRNA expressions of TLR6 and TLR1 was been enhanced significantly by ERV insertion in multiple tissues of 30-day piglets. TLRs play important roles in the innate immune response by interacting with adapter molecules, such as MYD88, TIRAP, Rac1 and Tollip, which are downstream genes of the TLR pathway[58]. With the help of the qPCR analyses, we also confirmed that all/most detected downstream genes of TLRs were also upregulated by ERV insertion in multiple tissues of 30-day piglets, suggesting that the ERV insertion not only increases the expressions of $T L R 6$ and $T L R 1$, but also triggers the expressions of their downstream genes.

The cytokines released by inflammatory cells are essential factors in resisting pathogen infection. When activated by pathogens, TLRs recruit adapter molecules and subsequently initiate downstream signaling pathway, resulting in the activation of transcription factor nuclear factor kappa B subunit (NF-kB) and the production of downstream inflammatory cytokines[59,60]. Higher TLR1 expression suggested better prognosis in patients with pancreatic ductal adenocarcinoma (PDAC)[10]. The mRNA expressions of major TLR genes including TLR1 and TLR6 of Tibetan pigs were higher in most immune tissues than those of Yorkshires, which may attribute to stronger innate immunity for Tibetan pigs[61]. And higher expression of TLRs were also associated with stronger disease resistance[60]. Yorkshire $\times$ Landrace $(Y L)$ pigs exhibited more serious clinical symptoms when artificially infected with porcine circovirus type 2 (PCV2) virus compared with Laiwu, which is a China native pig breed, indicating YL and Laiwu pigs display different susceptibility to PCV2 infection and Laiwu pigs seem to be more resistant for PCV2 virus. The serum levels 
of IL-6, IL-8, IL-12 and transforming growth factor beta 1 (TGF- $\beta 1$ ) in the PCV2 relatively resisting pigs of Laiwu also increased significantly more pronounced at the early infection stages than in YL pigs[62]. Here, consistent to the increased expression of genes in the TLR pathway due to ERV insertion, we found that the expressions of the important inflammatory factors including IL-6, IL-8, and TNFa were also been increased by ERV insertion in tissues of 30-day piglets, with significant increment of IL-6 and TNFa in the serum. Overall, these data strongly support that the 192 bp ERV insertions improves the expressions of TLR6, TLR1, and their downstream genes by acting as an enhancer and playing roles in the regulation of TLR pathway, which may not only alter the gene activities in the TLR pathway and inflammatory factors, but also cause phenotype variations during the immune response.

\section{Conclusions}

By using bioinformatics analysis and PCR-based verification, five RIPs, located in the $3^{\prime}$ flank of TLR3 gene, 5 flank of TLR5 gene, intron 1 of TLR6 gene, intron 1 of TLR7gene, and 3' flank of TLR8 gene, was identified respectively and uneven distribution in diverse pig breeds was observed. The 192 bp ERV insertion in the intron 1 of $T L R 6$ significantly increases the activity of the TLR6 promoter and multiple mini-promoters acting as an enhancer. Furthermore, the ERV insertion also enhances the expression of TLR6 and TLR1, the downstream genes (MyD88, Rac1, Rac1, Tollip) of TLR signaling pathway and the inflammatory factors (IL$6, I L-8, T N F a$ ) in diverse tissues of 30-day piglets, as well as the serum concentrations of IL-6 and TNFa. Thus, the $192 \mathrm{bp}$ ERV insertion allele is benefit for disease resistance and may be useful for molecular breeding of disease resistant animals.

\section{Material And Methods}

\section{RIP screen}

Ten $T L R$ genic and their flanking sequences ( $5 \mathrm{~kb} 5^{\prime}$ flank and $3 \mathrm{~kb} 3^{\prime}$ flank) were obtained from fifteen assembled non-reference genomes (Landrace, Yorkshire, Pietrain, Berkshire, Hampshire, Cross-breed of Yorkshire/Landrace/Duroc, Wuzhishan, Tibetan, Rongchang, Meishan, Bamei, Bama, and Jinhua, Goettingen, and Ellegaard Gottingen minipigs) and one reference genome (Duroc) deposited in NCBI database (https://www.ncbi.nlm.nih.gov/)to screen the structural variations by alignment with ClustalX program. Large structural variations (more than $50 \mathrm{bp}$ ) were remained for further analysis. Retrotransposon (SINE, LINE, and ERV) insertions were annotated by RepeatMasker (http://www.repeatmasker.org/) with a customer constructed library[51]. Promoters were predicted in http://www.cbs.dtu.dk/services/Promoter/.Transcription factor binding sites were searched at https://bip.weizmann.ac.il/toolbox/seq_analysis/promoters.html\#databases and CPGs islands were recognized in https://www.novopro.cn/tools/cpg_islands.html?tdsourcetag=s_pctim_aiomsg. The predicted large structural variations (more than $50 \mathrm{bp}$ ) overlapping with retrotransposon (SINE, LINE, and ERV) insertions were designated as RIPs. These RIPs were further evaluated in seven Chinese native pig breeds (Diannan small-ear Pigs, Erhualian, Wuzhishan, Bama, Tibet, Meishan, Fengjing Pigs ), three commercial pig breeds(Duroc, Landrace, Yorkshire), one cross breed (Sujiang) and wild boars (from Anhui province,Fujian province and Heilongjiang province) by PCR amplification(Vazyme, Nanjing, China). Fort each breed, two 
pooled DNA samples, each contained at least three animal samples, were used. Origins of pigs and primers used for RIP evaluation was listed in Table S2 and Table S3. All obtained RIPs were further confirmed by TA cloning (Tiangen, Beijing, China)following the manufacturer's instructions and sequencing.

\section{RIP Genotyping}

Totally, twelve breeds (Duroc, Landrace, Yorkshire, Erhualian, Meishan, Fengjing, Bama, Tibetan, Wuzhishan, Diannan small-ear, Sujiang, and Sicilian black) were used to genotype the RIP distribution. Among these breeds, Duroc, Landrace, and Yorkshire are three lean type breeds, Sicilian black, Erhualian, Meishan, and Fengjing are five fat type pigs and Bama, Diannan small-ear, Wuzhishan, and Tibetan are four miniature pigs. Erhualian, Meishan, Fengjing, Bama, Tibetan, Diannan small-ear, Wuzhishan, are Chinese native breeds, while Sujing is a middle-type pigs, which is a new cross breed with $62.5 \%$ Duroc, $18.75 \%$ Jiangquhia, and $18.75 \%$ Fengjing bloods. Sicilian black pigs are Italian native breeds. The genotype and the allele frequencies were calculated, and Hardy-Weinberg equilibrium were tested using $X^{2}$. Polymorphic information

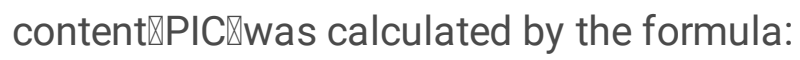

$$
P I C=1-\sum_{i=1}^{m} P_{i}^{2}-\sum_{i=1}^{m-1} \sum_{j=i+1}^{m} 2 P_{i}^{2} P_{j}^{2}
$$

\section{Dual luciferase reporter assay}

The predicted core promoter regions (NC_010450.4, 30171883-30172870) of TLR6 with and without the ERV insertion was cloned from the Sujiang genomic DNA (primers were listed in Table S2), and verified by sequencing. Then the clones were inserted into the pGL3-Basic vectors (Ambion, Austin, American) to construct TLR6 ${ }^{\text {ERV }}{ }_{-}$-Luc(En) vector and TLR6 ${ }^{\text {ERV }}{ }_{-}$Luc(En) Vector. In addition, $\beta$-globin and Oct4 mini-promoter were cloned from pEDV- $\beta$-globin-GFP and pTol2-Oct4-mCherry vector, respectively[63] and inserted into the pGL3-Basic vectors with or without the 192bp ERV for enhancer activity evaluation. A total of $2 \times 10^{4}$ PK15 and Hela cells were plated in a 24-well plates and transfected with the plasmids by using Lipofectamine 3000 reagent (Invitrogen, Carlsbad, American). After 48 hours, cells were collected for luciferase activity evaluation by using the dual luciferase reporter system (Promega, Madison, American) according to the manufacturer's protocol.

\section{Expression analysis}

The Sujing piglets were genotyped and five piglets for each genotype $\left(\mathrm{ERV}^{+/+}, \mathrm{ERV}^{+/-}\right.$, and $\left.\mathrm{ERV}^{-/}\right)$were selected and slaughtered to collect tissue samples at 30 days. The mRNAs were extracted and cDNAs were prepared according to the manufacturer's protocol by using TAKARA Kit(Takara,Tokyo,Japan). Then, the mRNA expressions of TLR6, TLR1, MyD88, RAC1, TOLLip, TIRAP, TNFa, IL-6, and IL-8 mRNA were evaluated by quantitative real-time PCR (qPCR) using the 7900HT Fast Real-Time PCR System (Applied Biosystems, new York, American) in a total volume of $20 \mu \mathrm{l}$ containing SYBR mix $(10 \mu \mathrm{l})$, primers $(4 \mathrm{ng})$, and cDNA sample (50 ng) according to the manufacturer's instructions (Takara,Tokyo, Japan). Glyceraldehyde-3phosphate dehydrogenase (GAPDH) was used as an endogenous control to normalize the target gene 
expression in four different tissues including liver, lung, kidney, and spleen. All gene expression was measured using the $2^{-\triangle \Delta C t}$ method. PCR products were run on $1.5 \%$ ethidium bromide-stained agarose gels and confirmed using melting curve analyses to assess PCR product quality.

\section{Measurement of serum TNFa, IL-6, and IL8 by enzyme linked immunosorbent assay (ELISA)}

TNFa, IL-6, IL8 concentration in serum of 30-day Sujian piglets were measured using the Pig TNFa, IL-6, and IL8 ELISA Kit (Solarbio Science, Beijing, China) by following the manufacturer's protocol. All measurements were performed in 3 replicates, and mean values were used for statistical analysis.

\section{Statistical analysis}

Experimental results were processed by statistical SPSS17.0 software package (SPSS, Chicago, USA) using one-way analysis of variance with Tukey's post hoc test, and the data were expressed as mean \pm S.D.

\section{Animal welfare}

All treatments and protocols involving animals in this study was been strictly done in accordance with the guidelines of the Animal Experiment Ethics Committee of Yangzhou University (approval number:

YZUDWSY2018-12).

\section{Abbreviations}

TLRs $\bigotimes$ Toll-like receptors

RIPs $₫$ Retrotransposon insertion polymorphisms

QTL『Quantitative trait locus

ERV: Endogenous retrovirus

PCR: Polymerase chain reaction

MyD88: Myeloid differentiation factor 88

Rac1: Rac family small GTPase 1

TIRAP: TIR domain containing adaptor protein

Tollip: Toll interacting protein

IL6: Interleukin 6

IL8: Interleukin 8

TNFa: Tumor necrosis factor alpha 
IFN-a: Interferon alpha 1

LTR: Long Terminal Repeat elements

SINE: Short Interspersed Nuclear Elements

ELISA: Enzyme linked immunosorbent assay

IRAP: Inter-retrotransposon amplified polymorphism

REMAP: Retrotransposon-microsatellite amplified polymorphism

NF-Kb: Nuclear factor kappa B subunit

PDAC: Pancreatic ductal adenocarcinoma

PCV2: Porcine circovirus type 2

TGF- $\beta 1$ : Transforming growth factor beta 1

\section{Declarations}

\section{Authors' contributions}

C.S. conceived the project; X.W. participated in its design; Z.C., E.M., E. D., Y.A. and C. C. performed animal trial, laboratory experiments, data collection and statistical analysis. X.W. and C.S. drafted the manuscript. K.L., G. G. and K. W. assisted in study design and review manuscript.The author(s) read and approved the final manuscript.

\section{Funding}

This work was supported by the Natural Science Foundation of China (31872977, 32002146), China Postdoctoral Science Foundation (2020M671630), and the Jiangsu Agriculture Science and Technology Innovation Fund [CX(19)2016]; and the Priority Academic Program Development of Jiangsu Higher Education Institutions and the High-end Talent Support Program of Yangzhou University.

\section{Availability of data and materials}

All data needed to evaluate the conclusions in this paper are present either in the main text or the Supporting information.

\section{Ethics approval and consent to participate}

Not applicable.

\section{Consent for publication}


Not applicable.

\section{Competing interests}

The authors declare that they have no competing interest.

\section{References}

1. Medzhitov R. Toll-like receptors and innate immunity. Nat Rev Immunol. 2001;1(2):135-145.

2. Medvedev AE. Toll-like receptor polymorphisms, inflammatory and infectious diseases, allergies, and cancer. J Interf Cytokine Res. 2013;33:467-84.

3. Vijay K. Toll-like receptors in immunity and inflammatory diseases: Past, present, and future. Int Immunopharmacol. 2018;59:391-412.

4. Dvornikova KA, Bystrova EY, Platonova ON, Churilov LP. Polymorphism of toll-like receptor genes and autoimmune endocrine diseases. Autoimmun Rev. 2020;19(4):102496.

5. Hawn TR, Wu H, Grossman JM, Hahn BH, Tsao BP, Aderem A. A stop codon polymorphism of Toll-like receptor 5 is associated with resistance to systemic lupus erythematosus. Proc Natl Acad Sci U S A. 2005;102(30): 10593-10597.

6. Quach H, Rotival M, Pothlichet J, Loh YHE, Dannemann M, Zidane N, et al. Genetic Adaptation and Neandertal Admixture Shaped the Immune System of Human Populations. Cell. 2016; 167(3):643-656. e617.

7. Dutta SK, Tripathi A. Association of toll-like receptor polymorphisms with susceptibility to chikungunya virus infection. Virology. 2017; 511:207-213.

8. Kawai T, Akira S. The role of pattern-recognition receptors in innate immunity: Update on toll-like receptors. Nat Immunol. 2010; 11(5):373-384.

9. Cinar MU, Hizlisoy H, Akyüz B, Arslan K, Aksel EG, Gümüşsoy KS. Polymorphisms in toll-like receptor (TLR) 1, 4, 9 and SLC11A1 genes and their association with paratuberculosis susceptibility in Holstein and indigenous crossbred cattle in Turkey. J Genet. 2018; 97(5):1147-1154.

10. Elmaghraby MM, El-Nahas AF, Fathala MM, Sahwan FM, Tag EL-Dien MA. Association of toll-like receptors 2 and 6 polymorphism with clinical mastitis and production traits in Holstein cattle. Iran J Vet Res. 2018;19(3): 202-207.

11. Fouad NA, Saeed AM, Mahedy AW. Toll Like Receptor-4 Gene Polymorphism and Susceptibility to Pulmonary Tuberculosis. Egypt J Immunol Egypt; 2019;26:1-10.

12. Uenishi H, Shinkai H. Porcine Toll-like receptors: The front line of pathogen monitoring and possible implications for disease resistance. Dev Comp Immunol. 2009;33:353-61.

13. Muneta Y, Arai N, Yakabe Y, Eguchi M, Shibahara T, Sakuma A, et al. In vivo effect of a TLR5 SNP (C1205T) on Salmonella enterica serovar Typhimurium infection in weaned, specific pathogen-free Landrace piglets. Microbiol Immunol. 2018; 62(6):380-387.

14. Shinkai H, Okumura N, Suzuki R, Muneta Y, Uenishi H. Toll-like receptor 4 polymorphism impairing lipopolysaccharide signaling in Sus scrofa, and its restricted distribution among Japanese wild boar 
populations. DNA Cell Biol. 2012; 31(4):575-581.

15. Yang XQ, Murani E, Ponsuksili S, Wimmers K. Association of TLR4 polymorphism with cytokine expression level and pulmonary lesion score in pigs. Mol Biol Rep. 2012;39(6):7003-7009.

16. Yang X, Murani E, Ponsuksili S, Wimmers K. Association of TLR5 sequence variants and mRNA level with cytokine transcription in pigs. Immunogenetics. 2013; 65(2):125-132.

17. Zeng L, Pederson SM, Kortschak RD, Adelson DL. Transposable elements and gene expression during the evolution of amniotes. Mob DNA. 2018;9:17.

18. Platt RN, Vandewege MW, Ray DA. Mammalian transposable elements and their impacts on genome evolution. Chromosom Res Chromosome Research; 2018;26:25-43.

19. Chuong EB, Elde NC, Feschotte C. Regulatory activities of transposable elements: From conflicts to benefits. Nat Rev Genet. 2017;18(2):71-86.

20. Orgel LE, Crick FHC. Selfish DNA: The ultimate parasite. Nature. 1980; 284(5757):604-607.

21. Hickey DA. Selfish DNA: A sexually transmitted nuclear parasite. Genetics. 1982; 101(3-4):519-531.

22. Garcia-Perez JL, Widmann TJ, Adams IR. The impact of transposable elements on mammalian development. Dev. 2016;143(22):4101-4114.

23. Arkhipova IR, Yushenova IA, Angert E. Giant Transposons in Eukaryotes: Is Bigger Better? Genome Biol Evol. 2019;11:906-18.

24. Kaaij LJT, Mohn F, van der Weide RH, de Wit E, Bühler M. The ChAHP Complex Counteracts Chromatin Looping at CTCF Sites that Emerged from SINE Expansions in Mouse. Cell. 2019; 178(6):14371451.e1414.

25. Kalendar R, Flavell AJ, Ellis THN, Sjakste T, Moisy C, Schulman AH. Analysis of plant diversity with retrotransposon-based molecular markers. Heredity (Edinb). 2011; 106(4):520-530.

26. Kalendar R, Amenov A, Daniyarov A. Use of retrotransposon-derived genetic markers to analyse genomic variability in plants. Funct. Plant Biol. 2018;46(1):15-29.

27. Payer LM, Burns KH. Transposable elements in human genetic disease. Nat Rev Genet. 2019; 20(12): 760-772.

28. Payer LM, Steranka JP, Yang WR, Kryatova M, Medabalimi S, Ardeljan D, et al. Structural variants caused by Alu insertions are associated with risks for many human diseases. Proc Natl Acad Sci U S A. 2017; 114(20):E3984-E3992.

29. Payer LM, Steranka JP, Ardeljan D, Walker J, Fitzgerald KC, Calabresi PA, et al. Alu insertion variants alter mRNA splicing. Nucleic Acids Res. 2019;47(1):421-431.

30. Chessa B, Pereira F, Arnaud F, Amorim A, Goyache F, Mainland I, et al. Revealing the history of sheep domestication using retrovirus integrations. Science. 2009;324(5926):532-536.

31. Kamath PL, Elleder D, Bao L, Cross PC, Powell JH, Poss M. The population history of endogenous retroviruses in mule deer (odocoileus hemionus). J Hered. 2014;105:173-87.

32. Ngo MH, Arnal M, Sumi R, Kawasaki J, Miyake A, Grant CK, et al. Tracking the Fate of Endogenous Retrovirus Segregation in Wild and Domestic Cats. J Virol. 2019; 93(24):e01324-01319 
33. Pettersson ME, Jern P. Whole-genome analysis of domestic chicken selection lines suggests segregating variation in ERV makeups. Genes (Basel). 2019; 10(2):162

34. Rivas-Carrillo SD, Pettersson ME, Rubin C-J, Jern P. Whole-genome comparison of endogenous retrovirus segregation across wild and domestic host species populations. Proc Natl Acad Sci. 2018;115(43):11012-11017.

35. Wragg D, Mwacharo JM, Alcalde JA, Wang C, Han JL, Gongora J, et al. Endogenous retrovirus EAV-HP linked to blue egg phenotype in Mapuche fowl. PLoS One. 2013;8(8):e71393.

36. Wang Z, Qu L, Yao J, Yang X, Li G, Zhang Y, et al. An EAV-HP Insertion in 5' Flanking Region of SLC01B3 Causes Blue Eggshell in the Chicken. PLoS Genet. 2013;9(1):e1003183.

37. Li J, Davis BW, Jern P, Dorshorst BJ, Siegel PB, Andersson L. Characterization of the endogenous retrovirus insertion in CYP19A1 associated with henny feathering in chicken. Mob DNA. Mobile DNA; 2019;10:1-8.

38. Magotra A, Naskar S, Das B, Ahmad T. A comparative study of SINE insertion together with a mutation in the first intron of follicle stimulating hormone beta gene in indigenous pigs of India. Mol Biol Rep. 2015;42:465-70.

39. Liu C, Ran X, Niu X, Li S, Wang J, Zhang Q. Insertion of 275-bp SINE into first intron of PDIA4 gene is associated with litter size in Xiang pigs. Anim Reprod Sci. 2018;195:16-23.

40. Larkin MA, Blackshields G, Brown NP, Chenna R, Mcgettigan PA, McWilliam H, et al. Clustal W and Clustal X version 2.0. Bioinformatics. 2007;23:2947-2948.

41. Jr. HHK. Mobile Elements: Drivers of Genome Evolution. Science. 2004;303:1626-32.

42. Vicient CM, Casacuberta JM. Impact of transposable elements on polyploid plant genomes. Ann Bot. 2017;120(2):195-207.

43. Orozco-Arias S, Isaza G, Guyot R. Retrotransposons in plant genomes: Structure, identification, and classification through bioinformatics and machine learning. Int. J. Mol. Sci. 2019;20(15):3837

44. Tollis M, Boissinot S. The evolutionary dynamics of transposable elements in eukaryote genomes. Repetitive DNA. 2012;7:68-91.

45. Kalendar R, Schulman AH. IRAP and REMAP for retrotransposon-based genotyping and fingerprinting. Nat Protoc. 2006;1(5):2478-2484.

46. Sorkheh K, Dehkordi MK, Ercisli S, Hegedus A, Halász J. Comparison of traditional and new generation DNA markers declares high genetic diversity and differentiated population structure of wild almond species. Sci Rep. 2017; 7(1):5966.

47. Kobayashi S, Goto-Yamamoto N, Hirochika H. Retrotransposon-Induced Mutations in Grape Skin Color. Science. 2004;304(5673):982.

48. Okada K, Wada M, Moriya S, Katayose Y, Fujisawa H, Wu J, et al. Expression of a putative dioxygenase gene adjacent to an insertion mutation is involved in the short internodes of columnar apples (Malus $\times$ domestica). J Plant Res. 2016;129(6):1109-1126.

49. Han M, Sun Q, Zhou J, Qiu H, Guo J, Lu L, et al. Insertion of a solo LTR retrotransposon associates with spur mutations in 'Red Delicious' apple (Malus × domestica). Plant Cell Rep. 2017;36(9):1375-1385. 
50. Ray DA. SINEs of progress: Mobile element applications to molecular ecology. Mol. Ecol. 2007;16(1): 19-33.

51. Chen C, Wang W, Wang X, Shen D, Wang S, Wang Y, et al. Retrotransposons evolution and impact on IncRNA and protein coding genes in pigs. Mob DNA. Mobile DNA; 2019;10:1-24.

52. Bourque G, Burns KH, Gehring M, Gorbunova V, Seluanov A, Hammell M, et al. Ten things you should know about transposable elements. Genome Biol. 2018;19(1):199.

53. Henikoff S, Greene EA, Pietrokovski S, Bork P, Attwood TK, Hood L. Gene families: The taxonomy of protein paralogs and chimeras. Science. 1997;278(5338):609-614.

54. Feuchter-murthy AE, Freeman JD, Mager DL. Splicing of a human endogenous retrovirus to a novel phospholipase A2 related gene. Nucleic Acids Res. 1993;21(1):135-143.

55. Schulte AM, Lai S, Kurtz A, Czubayko F, Riegel AT, Wellstein A. Human trophoblast and choriocarcinoma expression of the growth factor pleiotrophin attributable to germ-line insertion of an endogenous retrovirus. Proc Natl Acad Sci U S A. 1996; 93(25):14759-14764.

56. Beyer U, Moll-Rocek J, Moll UM, Dobbelstein M. Endogenous retrovirus drives hitherto unknown proapoptotic p63 isoforms in the male germ line of humans and great apes. Proc Natl Acad Sci U S A. 2011;108(9):3624-3629.

57. Butler JE, Wertz N. The porcine antibody repertoire: Variations on the textbook theme. Front Immunol. 2012; 3:153.

58. Frazão JB, Errante PR, Condino-Neto A. Toll-like receptors' pathway disturbances are associated with increased susceptibility to infections in humans. Arch. Immunol. Ther Exp (Warsz). 2013;61(6):427443.

59. Li X, Jiang S, Tapping RI. Toll-like receptor signaling in cell proliferation and survival. Cytokine. 2010;49(1): 1-9.

60. O'Neill LAJ, Golenbock D, Bowie AG. The history of Toll-like receptors-redefining innate immunity. Nat Rev Immunol. 2013;13(6):453-460.

61. Cheng C, Sun WK, Liu R, Wang RM, Chen YH, Wang Y, et al. Comparison of gene expression of Toll-like receptors and antimicrobial peptides in immune organs and tissues between Yorkshire and Tibetan pigs. Anim Genet. 2015;46(3):272-279.

62. Li Y, Liu H, Wang P, Wang L, Sun Y, Liu G, et al. RNA-seq analysis reveals genes underlying different disease responses to porcine circovirus type 2 in pigs. PLoS One. 2016;11(5):e0155502.

63. Chan S, Shen D, Sang Y, Wang S, Wang Y, Chen C, et al. Development of enhancer-trapping anddetection vectors mediated by the Tol2 transposon in zebrafish. PeerJ. 2019; 7:e6862.

\section{Tables}

Table 1. Genotype and allele frequency of five RIPs in the RIP-polymorphic breeds 


\begin{tabular}{|c|c|c|c|c|c|c|c|c|c|}
\hline \multirow[t]{2}{*}{ RIP } & \multirow[t]{2}{*}{ Breed } & \multirow[t]{2}{*}{$\mathbf{N}$} & \multicolumn{2}{|c|}{ Genotype/\% } & \multicolumn{3}{|c|}{ Allele/\% } & \multirow{2}{*}{$\begin{array}{l}\text { Hardy- } \\
\text { Weinberg/P }\end{array}$} & \multirow[t]{2}{*}{ PIC } \\
\hline & & & $+/+$ & $+/-$ & - & + & - & & \\
\hline \multirow{6}{*}{$\begin{array}{l}\text { TLR3-SINE- } \\
\text { RIP }\end{array}$} & Duroc & 24 & 0 & 16.67 & 83.33 & 8.33 & 91.67 & 0.656 & 0.141 \\
\hline & Erhualian & 24 & 25.00 & 45.83 & 29.17 & 47.92 & 52.08 & 0.689 & 0.375 \\
\hline & Bama & 30 & 3.33 & 60.00 & 36.67 & 33.33 & 66.67 & 0.552 & 0.346 \\
\hline & Tibetan & 35 & 0 & 17.14 & 82.86 & 8.57 & 91.43 & 0.579 & 0.144 \\
\hline & Meishan & 24 & 37.50 & 29.17 & 33.33 & 52.08 & 47.92 & 0.042 & 0.375 \\
\hline & Fengjing & 23 & 47.83 & 39.13 & 13.04 & 67.39 & 32.61 & 0.599 & 0.343 \\
\hline \multirow{3}{*}{$\begin{array}{l}\text { TLR5-LINE- } \\
\text { RIP- }\end{array}$} & Duroc & 24 & 4.17 & 62.50 & 33.33 & 35.42 & 64.58 & 0.073 & 0.353 \\
\hline & Yorkshire & 24 & 8.33 & 41.67 & 50 & 29.17 & 70.83 & 0.967 & 0.328 \\
\hline & Wuzhishan & 24 & 29.17 & 50.00 & 20.83 & 54.17 & 45.83 & 0.973 & 0.373 \\
\hline \multirow{8}{*}{$\begin{array}{l}\text { TLR6ERV- } \\
\text { RIP }\end{array}$} & Sujiang & 163 & 52.76 & 20.86 & 26.38 & 63.19 & 36.81 & $1.89^{\mathrm{e}-12}$ & 0.357 \\
\hline & Erhualian & 36 & 27.78 & 22.22 & 50.00 & 38.89 & 61.11 & 0.001 & 0.362 \\
\hline & Bama & 43 & 44.19 & 39.53 & 16.28 & 63.95 & 36.05 & 0.350 & 0.355 \\
\hline & Fengjing & 24 & 41.67 & 58.33 & 0 & 70.83 & 29.17 & 0.044 & 0.328 \\
\hline & $\begin{array}{l}\text { Yorkshire } \\
\text { (German) }\end{array}$ & 31 & 100 & 0 & 0 & 100 & 0 & 1 & 0 \\
\hline & $\begin{array}{l}\text { Sicilian } \\
\text { black }\end{array}$ & 30 & 100 & 0 & 0 & 100 & 0 & 1 & 0 \\
\hline & (Italy) & & & & & & & & \\
\hline & $\begin{array}{l}\text { Landrace } \\
\text { (German) }\end{array}$ & 32 & 100 & 0 & 0 & 100 & 0 & 1 & 0 \\
\hline \multirow{6}{*}{$\begin{array}{l}\text { TLR7ERV- } \\
\text { RIP }\end{array}$} & Landrace & 18 & 0 & 83.33 & 16.67 & 41.67 & 58.33 & 0.002 & 0.368 \\
\hline & Wuzhishan & 23 & 0 & 43.48 & 56.52 & 21.74 & 78.26 & 0.183 & 0.282 \\
\hline & Landrace & 24 & 75.00 & 16.67 & 8.33 & 83.33 & 16.67 & 0.050 & 0.239 \\
\hline & Yorkshire & 24 & 62.50 & 29.17 & 8.33 & 77.08 & 22.92 & 0.393 & 0.291 \\
\hline & Sujiang & 24 & 50.00 & 45.83 & 4.17 & 72.92 & 27.08 & 0.432 & 0.317 \\
\hline & Wuzhishan & 23 & 43.48 & 26.09 & 30.43 & 56.52 & 43.48 & 0.024 & 0.371 \\
\hline
\end{tabular}

Eleven breeds (Duroc, Landrace, Yorkshire, Erhualian, Meishan, Fengjing, Bama, Tibetan,Wuzhishan, Diannan small-ear, and Sujiang) were used for all RIP evaluation, extra breeds of Sicilian black from Italy and Saddleback from Germany were used for TLR6-ERV-RIP evaluation. Only the breeds display polymorphic 
RIPs in Fig.1A were tested by increasing individuals except Diannan small-ear pig. Polymorphic information content (PIC) was measured by using the formula as described in materials and methods. The HardyWeinberg was detected by $\mathrm{X}^{2}$ test, and the $\mathrm{P}<0.05$ indicates that the RIP distribution is deviated from the Hardy-weinberg equilibrium.

\section{Figures}

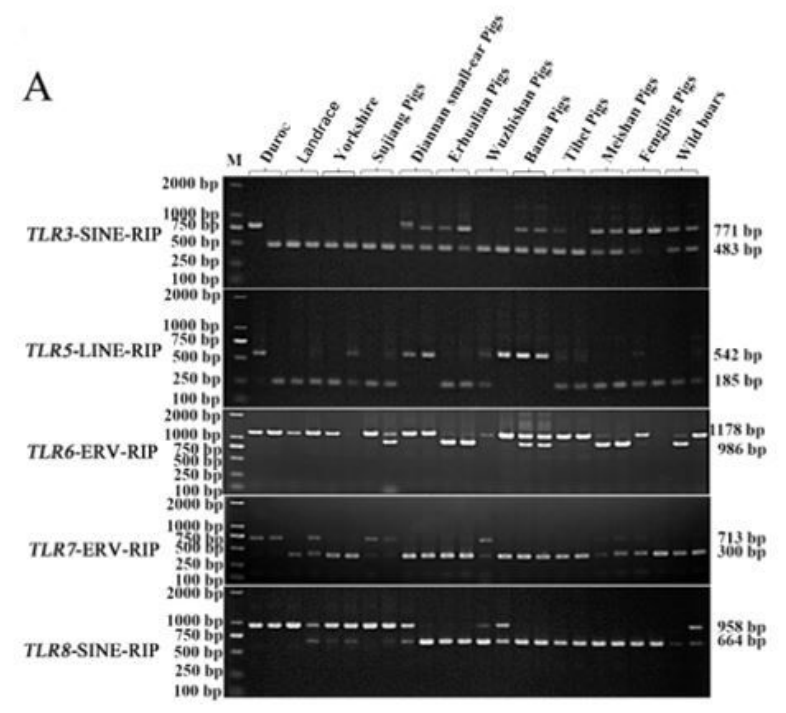

\section{B}

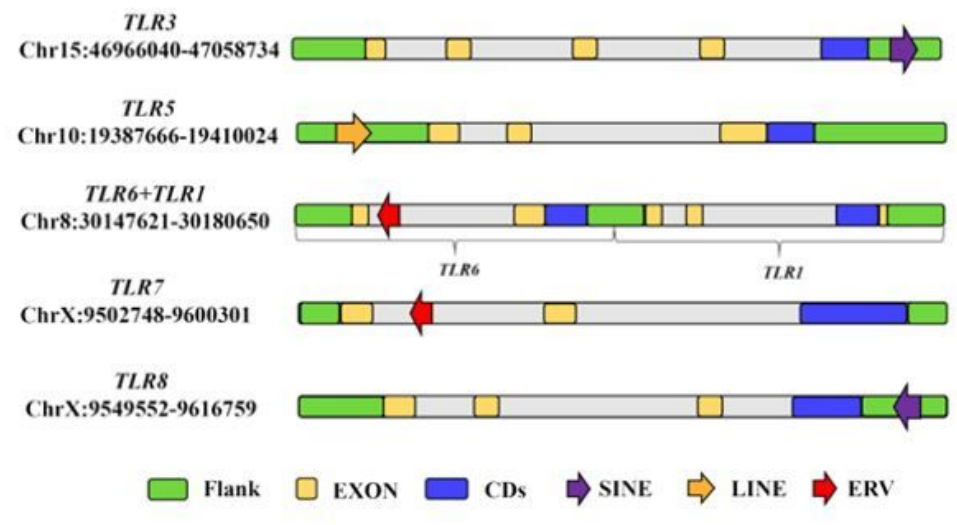

C

\begin{tabular}{|c|c|c|c|c|c|}
\hline Name & Classification & Length & Location & Direction & Polymorphic breeds in DNApool \\
\hline TLR3-SINE-RIP & SINEA1 & 288 bp & 3' Flank & + & $\begin{array}{c}\text { Duroc, Diannan small-ear pigs, Erhualian pigs, Bama pigs, Tibet } \\
\text { pigs, Meishan pigs, Fengjing pigs, Wild boars }\end{array}$ \\
\hline TLR5-LINE-RIP & LINE L1 & $357 \mathrm{bp}$ & 5'Flank & + & Duroc, Yorkshire, Wuzhishan pigs \\
\hline TLR6-ERV-RIP & ERV18 & $192 \mathrm{bp}$ & Intron 1 & - & Sujiang pigs, Bama pigs, Fengjing pigs, Wild boars \\
\hline TLR7-ERV-RIP & ERV6A & $413 \mathrm{bp}$ & Intron 1 & - & Landrace, Wuzhishan pigs \\
\hline TLR8-SINE-RIP & SINEAI & 294 bp & 3'Flank & - & $\begin{array}{l}\text { Landrace, Yorkshire, Sujiang pigs, Diannan small-ear pigs, } \\
\text { Wuzhishan pigs, Wild boars }\end{array}$ \\
\hline
\end{tabular}

\section{Figure 1}

PCR identification and characteristic of RIP in TLRs. A: RIP identification in DNA pool by PCR; B: location of retrotransposon insertion in TLRs; C: characteristic of RIPs in TLRs. 


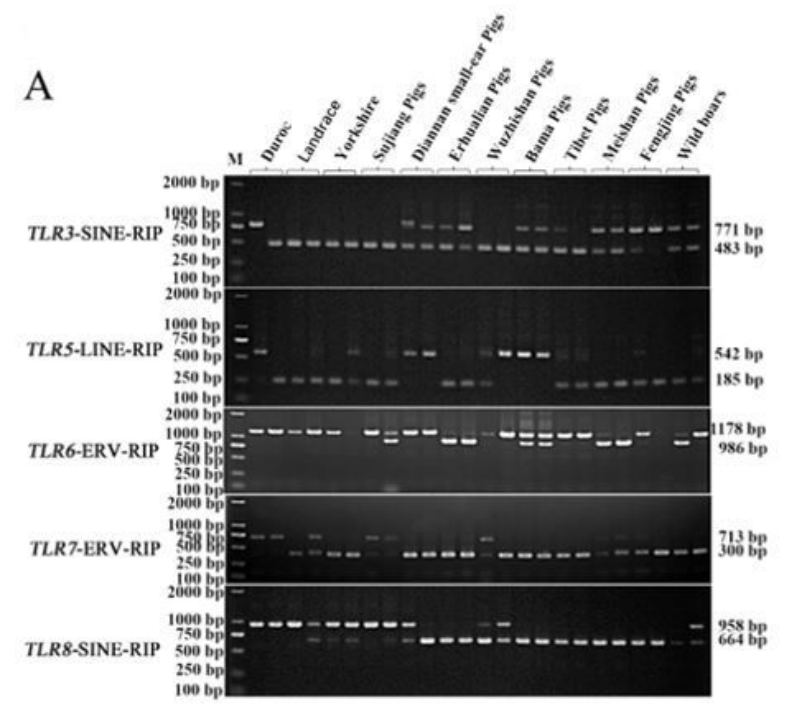

B

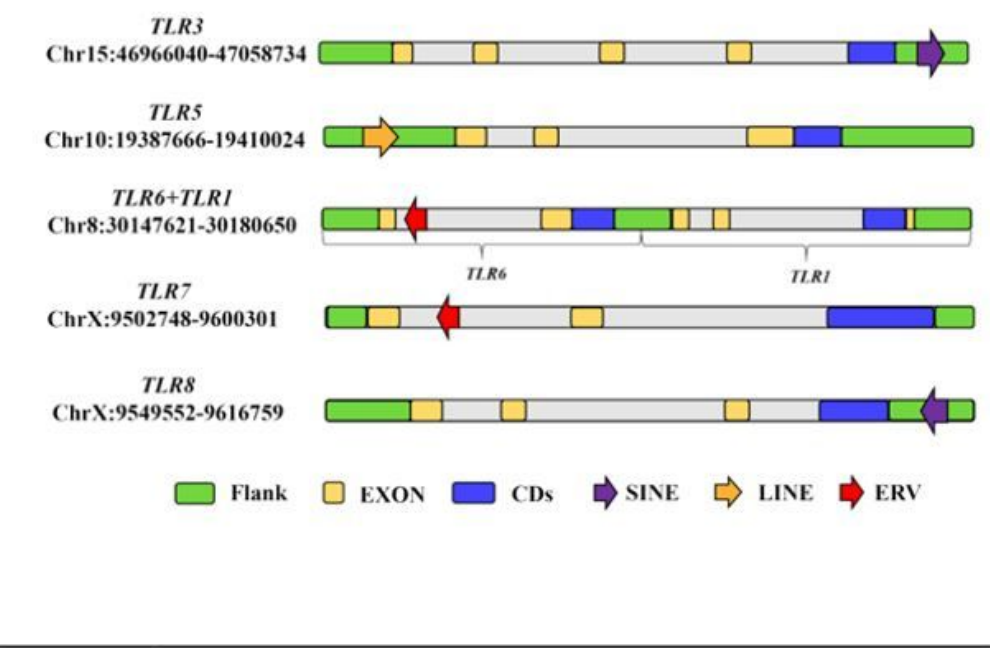

\begin{tabular}{cccccc}
\hline Name & Classification & Length & Location & Direction & Polymorphic breeds in DNA pool \\
\hline TLR3-SINE-RIP & SINEAl & $288 \mathrm{bp}$ & 3' Flank & + & Duroc, Diannan small-ear pigs, Erhualian pigs, Bama pigs, Tibet \\
TLR5-LINE-RIP & LINE L1 & $357 \mathrm{bp}$ & 5'Flank & + & pigs, Meishan pigs, Fengjing pigs, Wild boars \\
TLR6-ERV-RIP & ERV18 & $192 \mathrm{bp}$ & Intron 1 & - & Duroc, Yorkshire, Wuzhishan pigs \\
TLR7-ERV-RIP & ERV6A & $413 \mathrm{bp}$ & Intron 1 & - & Sujiang pigs, Bama pigs, Fenging pigs, Wild boars \\
& & & & Landrace, Wuzhishan pigs
\end{tabular}

\section{Figure 1}

PCR identification and characteristic of RIP in TLRs. A: RIP identification in DNA pool by PCR; B: location of retrotransposon insertion in TLRs; C: characteristic of RIPs in TLRs. 

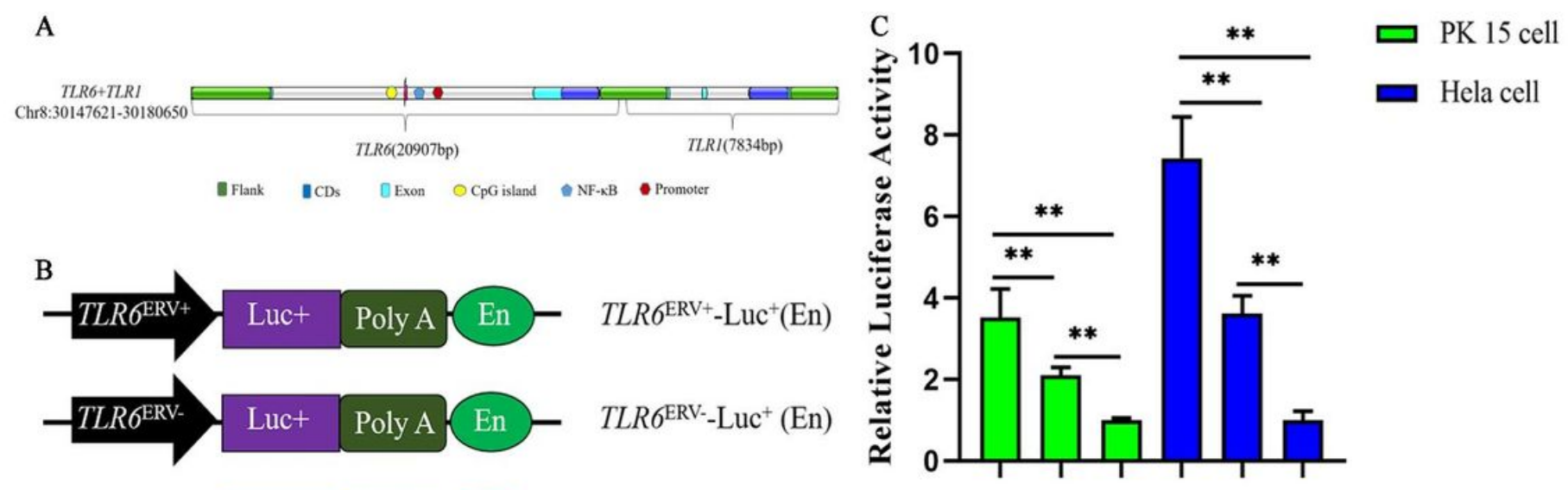

\section{Luc+ Poly A En - $\operatorname{Luc}^{+}($En)}

\section{Figure 2}

Effect of ERV insertion on TLR6 promoter activity. A: sequence analysis of pig TLR6 and TLR1; B: a schematic diagram of the recombinant vector using pGL3-basic vector. En: SV40 enhancer; C: the luciferase activity assays. ${ }^{\star \star}$ showed $P<0.01$ between groups $(P<0.01)$.
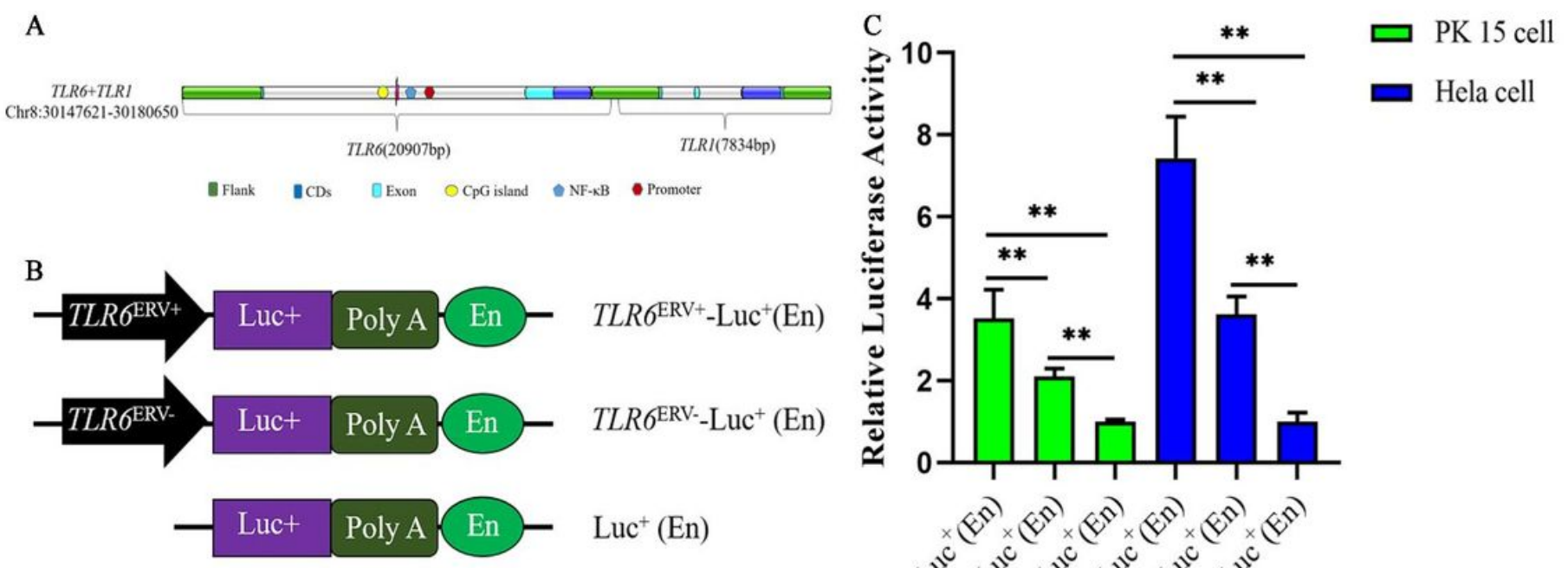

\section{Figure 2}

Effect of ERV insertion on TLR6 promoter activity. A: sequence analysis of pig TLR6 and TLR1; B: a schematic diagram of the recombinant vector using pGL3-basic vector. En: SV40 enhancer; C: the luciferase activity assays. ${ }^{*}$ showed $\mathrm{P}<0.01$ between groups $(\mathrm{P}<0.01)$. 
A

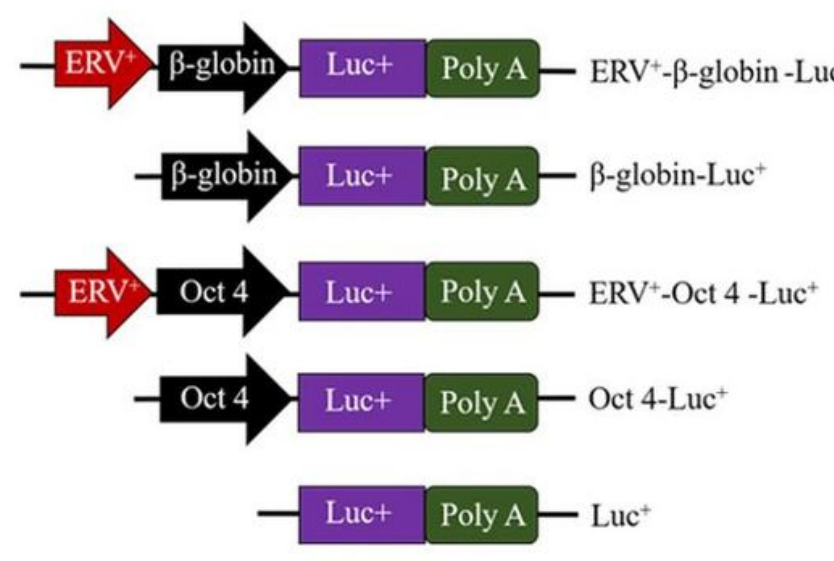

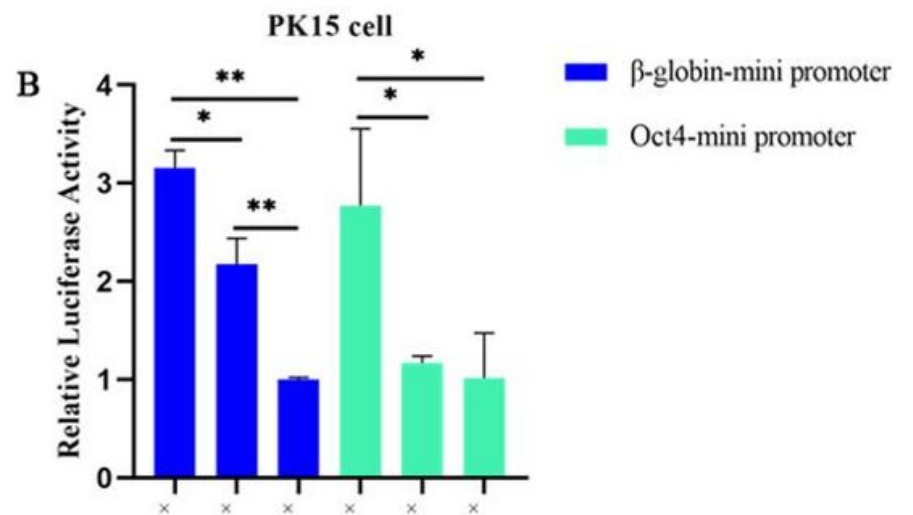
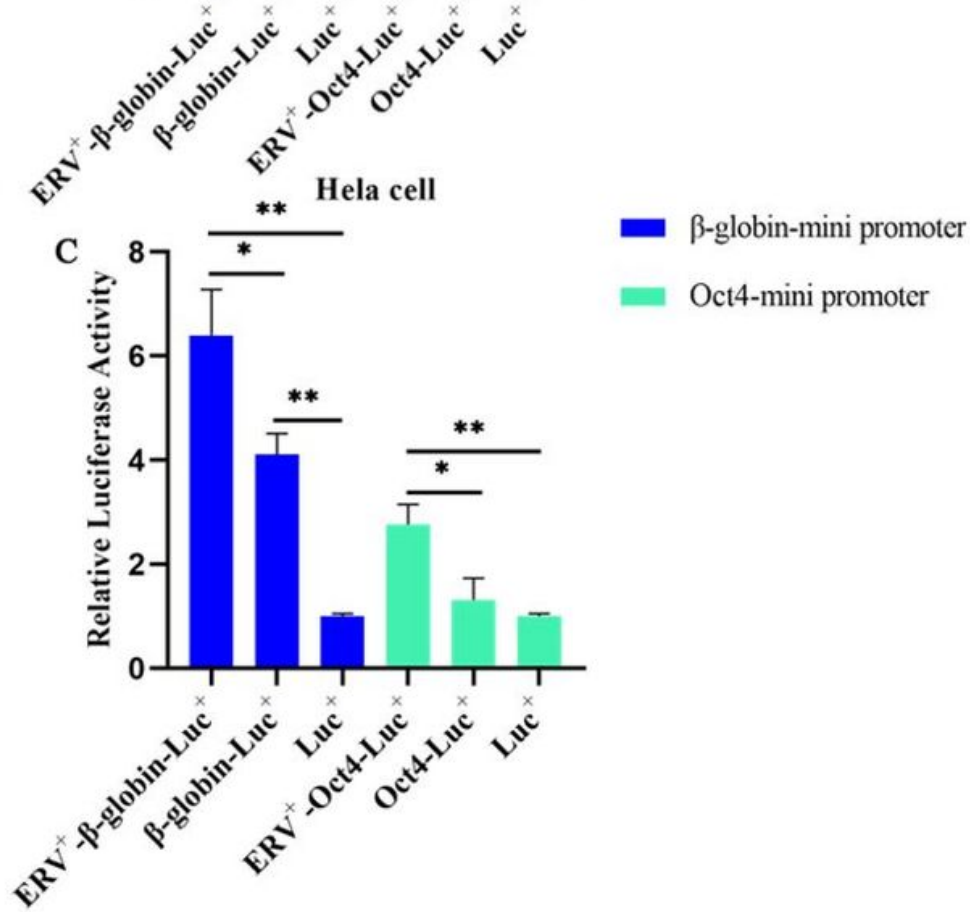

\section{Figure 3}

Effect of ERV insertion on mini promoter activity. A: plasmid diagram of the recombinant vector using pGL3basic vector; $B$ : the luciferase activity assays of ERV on activity of $\beta$ globin and Oct4 in PK15; C: the luciferase activity assays of ERV on activity of $\beta$ globin and Oct4 in Hela cell. * showed $\mathrm{P}<0.05$; ${ }^{* *}$ showed $\mathrm{P}<0.01$. 
A
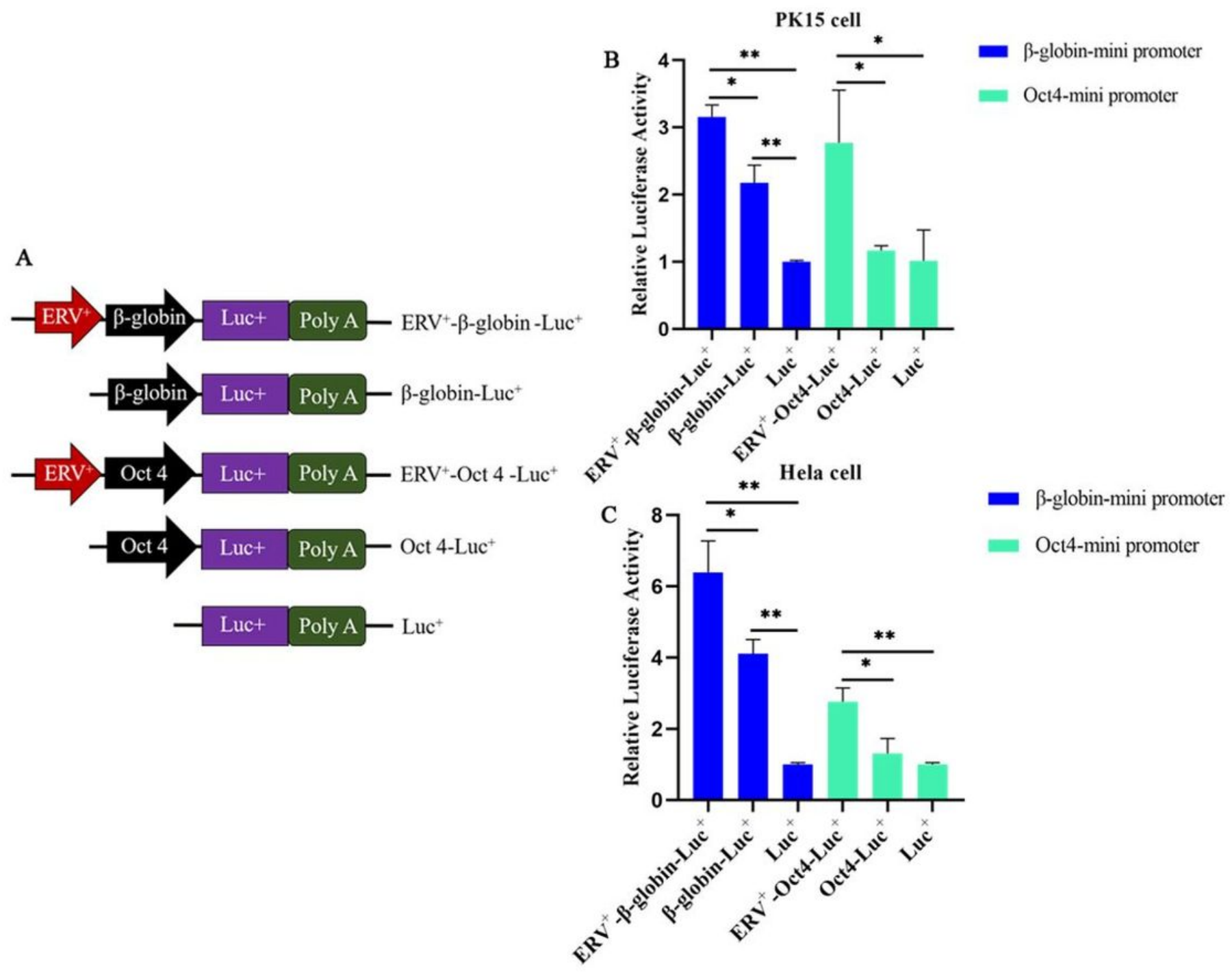

Figure 3

Effect of ERV insertion on mini promoter activity. A: plasmid diagram of the recombinant vector using pGL3basic vector; $B$ : the luciferase activity assays of ERV on activity of $\beta$ globin and Oct4 in PK15; C: the luciferase activity assays of ERV on activity of $\beta$ globin and Oct4 in Hela cell. * showed $P<0.05$; $* \star$ showed $\mathrm{P}<0.01$. 

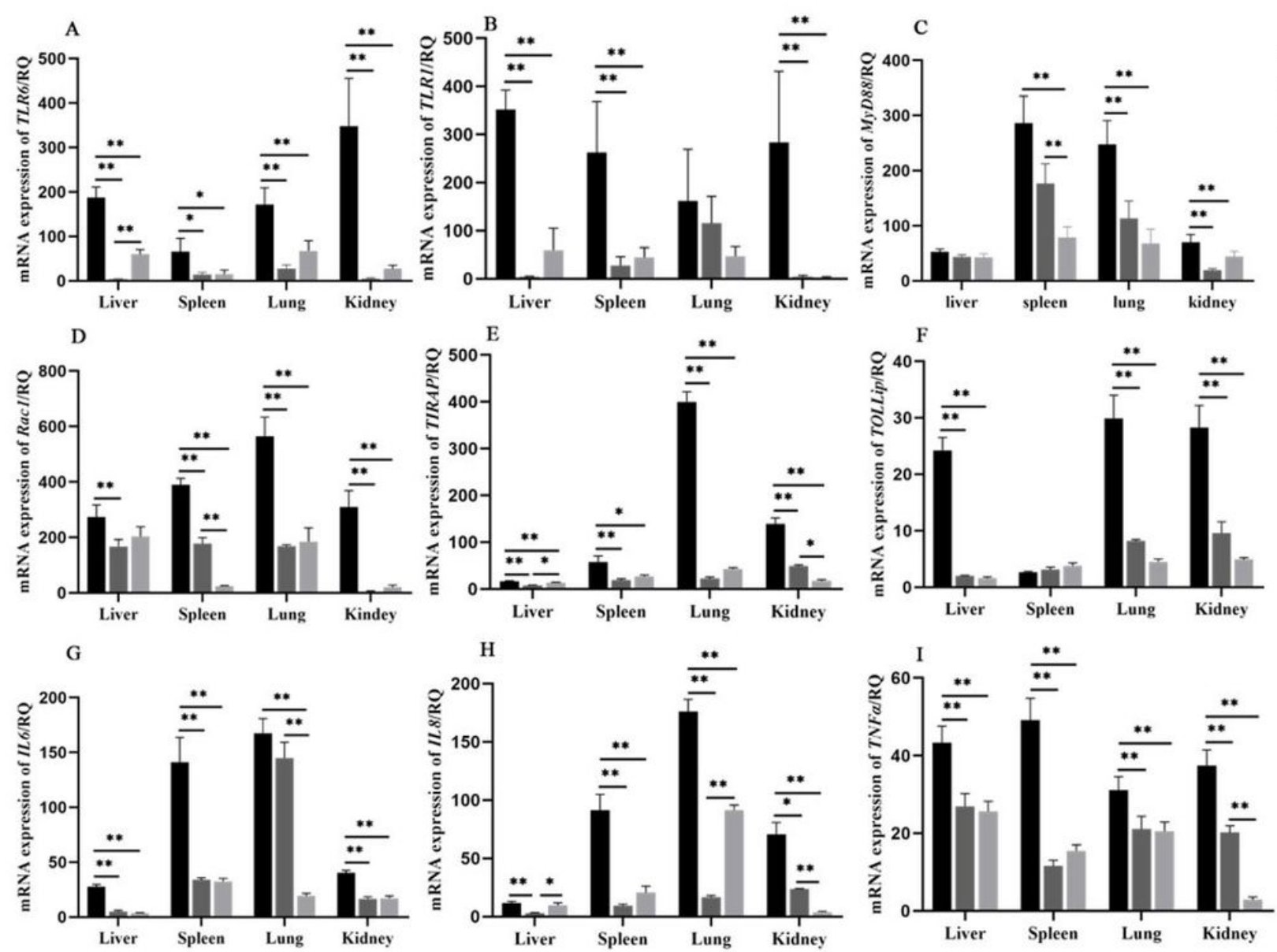

Figure 4

Effect of ERV insertion on expression of TLR6(A), TLR1(B) and downstream genes Myd88 (C) , Rac1 (D), TIRAP (E), TOLLip (F), IL6 (G), IL8 (H), TNFa (I) of TOLL like receptor signaling pathway in different organs or tissues of 30-day old piglets. * showed $\mathrm{P}<0.05$; $* \star$ showed $\mathrm{P}<0.01$. 

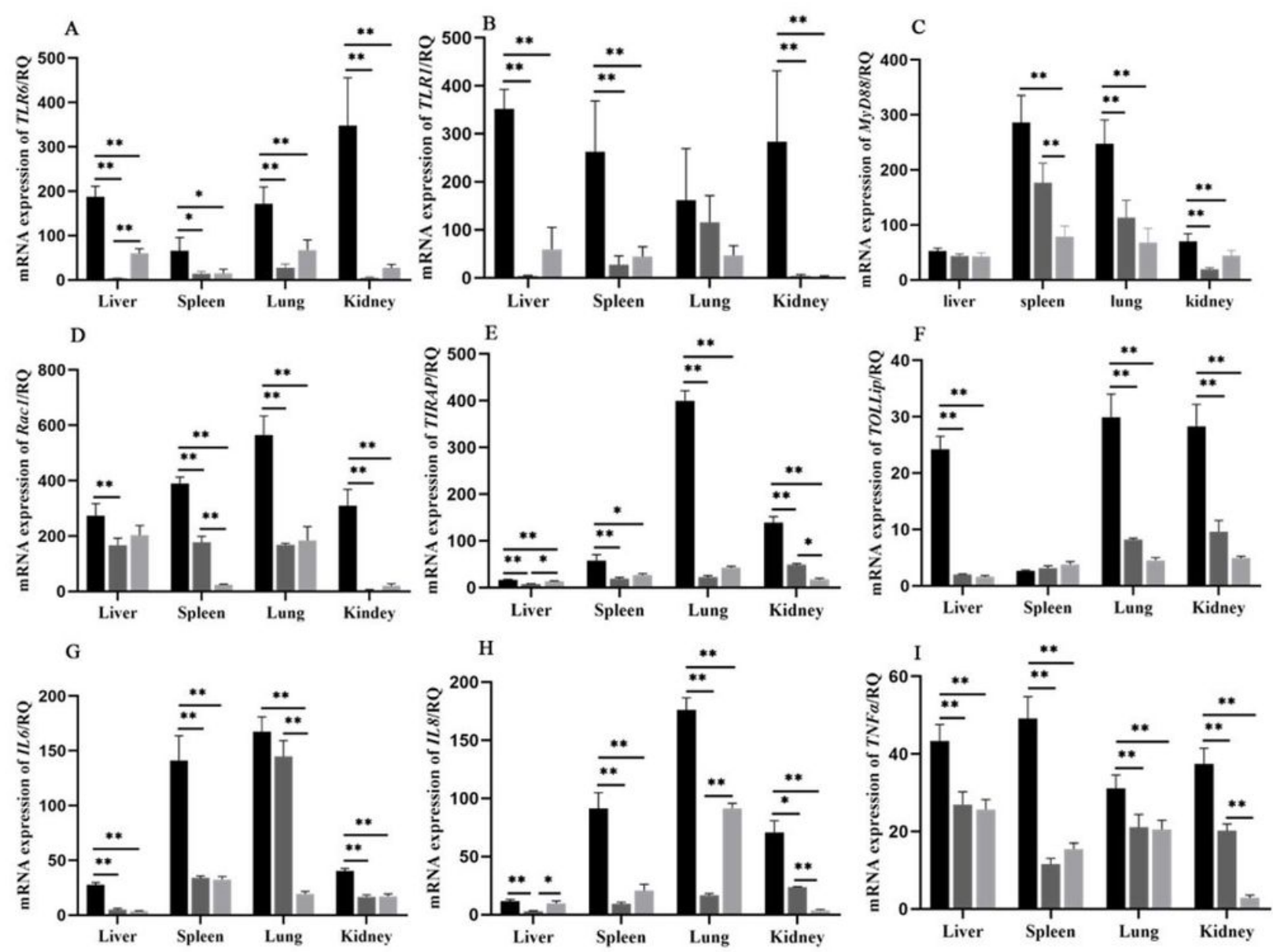

Figure 4

Effect of ERV insertion on expression of TLR6(A), TLR1(B) and downstream genes Myd88 (C) , Rac1 (D), TIRAP (E), TOLLip (F), IL6 (G), IL8 (H), TNFa (I) of TOLL like receptor signaling pathway in different organs or tissues of 30-day old piglets. * showed $\mathrm{P}<0.05$; $* \star$ showed $\mathrm{P}<0.01$. 


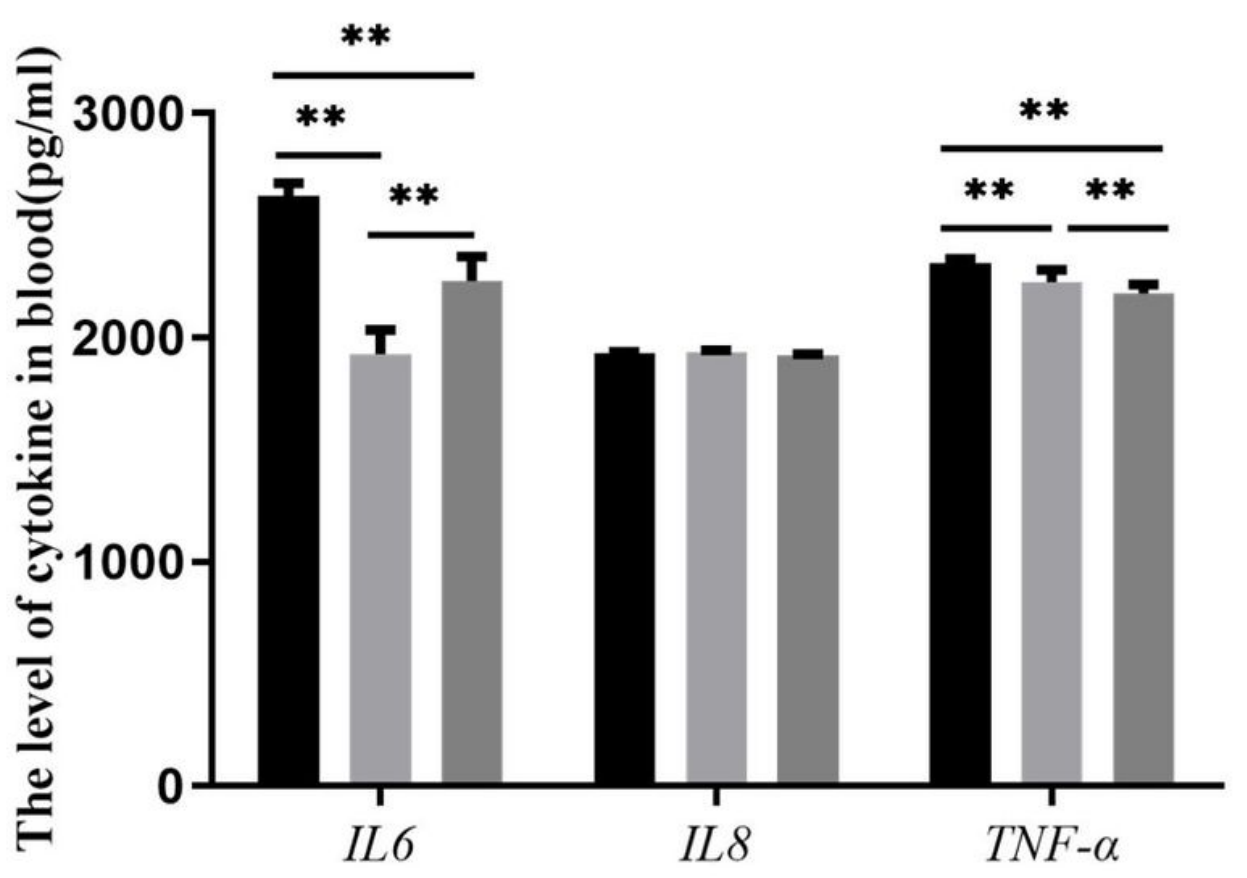

- TLR6-ERV ${ }^{+/+}$-RIP

TLR6-ERV ${ }^{+/-}$-RIP

TLR6-ERV ${ }^{-/-}$-RIP

Figure 5

The level of cytokine in blood of different TLR6-ERV-RIP genotypes; * showed $\mathrm{P}<0.05 ;{ }^{\star \star}$ showed $\mathrm{P}<0.01$.

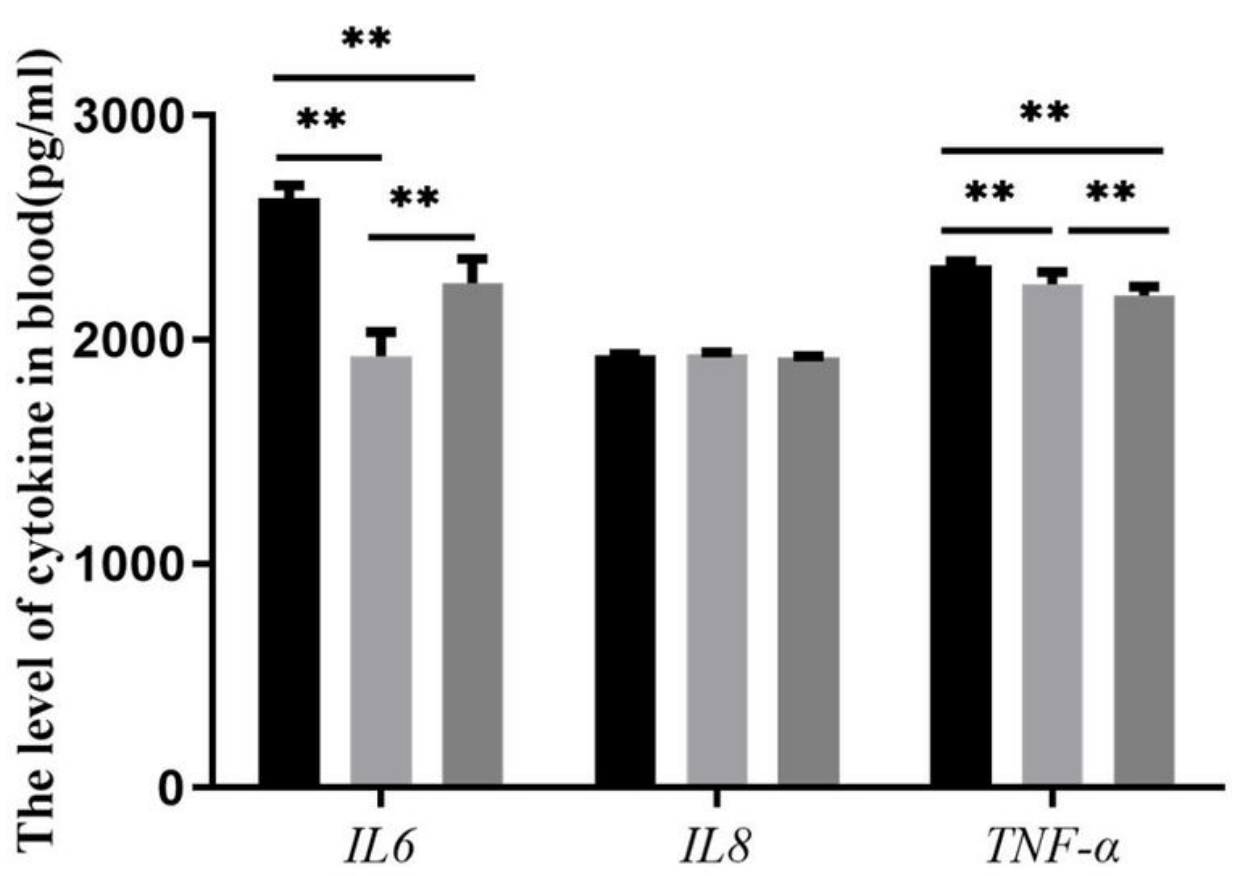

- TLR6-ERV ${ }^{+/+}-\mathrm{RIP}$

TLR6-ERV ${ }^{+/-}$-RIP

TLR6-ERV ${ }^{-/-}$-RIP

Figure 5 
The level of cytokine in blood of different TLR6-ERV-RIP genotypes; * showed $\mathrm{P}<0.05$; ${ }^{\star \star}$ showed $\mathrm{P}<0.01$.

\section{Supplementary Files}

This is a list of supplementary files associated with this preprint. Click to download.

- Supplementrytable123.docx

- Supplementrytable123.docx 